\title{
Video Article \\ Implantation of a New Micro Acoustic Tag in Juvenile Pacific Lamprey and American Eel
}

\author{
Robert Mueller ${ }^{1}$, Stephanie Liss ${ }^{1}$, Z. Daniel Deng ${ }^{1}$ \\ ${ }^{1}$ Earth Systems Science Division, Pacific Northwest National Laboratory \\ Correspondence to: Robert Mueller at robert.mueller@pnnl.gov \\ URL: https://www.jove.com/video/59274 \\ DOI: doi:10.3791/59274
}

Keywords: Environmental Sciences, Issue 145, Pacific Lamprey, American Eel, tagging, acoustic transmitters, swimming ability, tag shedding Date Published: 3/16/2019

Citation: Mueller, R., Liss, S., Deng, Z.D. Implantation of a New Micro Acoustic Tag in Juvenile Pacific Lamprey and American Eel. J. Vis. Exp. (145), e59274, doi:10.3791/59274 (2019).

\section{Abstract}

Juvenile Pacific Lamprey and American eels were used for laboratory evaluations to determine potential effects from tag implantation. Telemetry technology has been identified as a way to obtain more detailed information on movement and behavior across a broader spatial scale than is possible with other known technology. The purpose of this method is to provide a detailed step by step instruction on tag implantation for both lampreys and eel. For laboratory studies using actively migrating juvenile Pacific Lamprey (120-160 mm), we determined that the presence of the tag did not alter the swimming ability between tagged and untagged Individuals or have any significant tag loss $(<3 \%)$. Similar results were determined during laboratory testing of Yellow phase American Eels (113-175 mm). No mortality occurred during a 38-day holding period and there was minimal tag loss (3.8\%). The presence of the tag did not have any significant effect on the swimming ability or survival of tagged eels compared to untagged controls and there was minimal tag loss.

\section{Video Link}

The video component of this article can be found at https://www.jove.com/video/59274/

\section{Introduction}

Understanding fish behavior and movements near river structures, such as hydropower dams, that may impede upstream or downstream migration routes is an ongoing research need. Although numerous studies have been conducted using existing technology, there are still many research questions about juvenile eels and lamprey survival and behavior. To help address these questions, Pacific Northwest National Laboratory (PNNL) has developed a new acoustic micro transmitter specifically designed for use in juvenile eels and lampreys, called the lamprey/eel tag ${ }^{1}$. Prior to this development, existing acoustic tags were too large to be effectively implanted into the body cavities of juvenile eels and lampreys, and would result in a tag burden that exceeds accepted standards (a conservative value of tag to body weight ratio is $2 \%$ or less and other literature suggests $4-5 \%)^{2,3,4}$. The lamprey/eel tags emit unique coded signals at a frequency of $416.7 \mathrm{kHz}$, which are monitored via autonomous receivers (hydrophones) at fixed structures or in-river receivers ${ }^{5,6}$.

In the Columbia River Basin in the United States, awareness and concern for understanding the entire life cycle of the Pacific Lamprey (Entosphenus tridentatus) has escalated because populations have significantly declined in the past 40 years ${ }^{7}$. Construction and operation of hydroelectric facilities may negatively affect juvenile lamprey, as their declines occurred after the period of major hydroelectric development ${ }^{8}$. One potential source of mortality is dam passage when juvenile Pacific Lamprey out-migrate to the ocean ${ }^{9}$. Passive Integrated Transponders (PIT) are commonly used for migrating fish species that may pass diversion structures (e.g., juvenile bypass systems), which allows tagged fish to be enumerated ${ }^{10,11}$. However, juvenile lamprey are thought to migrate deeper in the water column than juvenile salmon and are less likely to pass through the juvenile bypass systems ${ }^{12}$. Because of the low detection probabilities and a lack of hatcheries or other concentrated sources of juvenile lamprey for PIT tagging, information on juvenile lamprey passage, survival, or behavior is very limited. Knowledge of juvenile Pacific Lamprey behavior and survival are critical for developing mitigation strategies for downstream passage, including design of bypass systems for use at hydroelectric facilities and irrigation diversion structures ${ }^{13}$.

The American eel (Anguilla rostrata) is catadromous with the adult phase migrating from freshwater toward the ocean to spawn. Their population levels have seen dramatic declines over the past several decades. Previously, they were very abundant in all major rivers flowing into the Atlantic Ocean and upstream through the St. Lawrence River to Lake Ontario; but since 1980, American eels have experienced significant declines in stock abundance ranging from $50 \%$ in Chesapeake Bay to as much as $97 \%$ in Lake Ontario ${ }^{14,15,16}$. The factors contributing to their decline include; the construction of hydroelectric dams, fragmentation and loss of habitat, and commercial harvesting ${ }^{17}$. They are currently listed as Endangered under the Ontario (Canada) Endangered Species Act. The past development of hydropower facilities along major rivers of Eastern U.S. states create obstacles that impede riverine migrations of both juveniles and adults.

The newly developed lamprey/eel acoustic tag was used in this study. The tags were manufactured at PNNL's accredited Bio-Acoustics \& Flow Laboratory ${ }^{18}$. The tag measures $12 \mathrm{~mm}$ length $\times 2 \mathrm{~mm}$ diameter, and has a weight of $0.08 \mathrm{~g}$ in air. Because of the tag's small overall size, it can be effectively used for implantation into anguilliform or juvenile fish using a sutureless incision, due to the small incision required $(<3 \mathrm{~mm}$ long). 
Additional benefits of sutureless incision include: a reduced amount of time required for surgical process, faster healing rates, and decreased possibility of infections at the implantation site ${ }^{19}$. Surgical implantation effects can vary in response to species, life stage, body cavity length, incision location, study duration, and environmental conditions ${ }^{20,21,22,23}$. In addition to size, weight is an important variable because it provides a measure of the tag burden (i.e., the weight of the tag relative to the weight of the fish). The tag burden, in association with all other aspects of the surgical process (e.g., anesthesia, handling, surgery), can have a direct effect on tag retention, survival, growth, swimming performance, or the ability of fish to avoid predation ${ }^{24,25,26,27}$.

\section{Protocol}

PNNL is accredited by the Association for Assessment and Accreditation of Laboratory Animal Care. Eels and lamprey were handled in accordance with federal guidelines for the care and use of laboratory animals, and the protocols for our study were conducted in compliance with and approved by PNNL's Institutional Animal Care and Use Committee.

\section{Tag preparation (timing 22 minutes)}

1. Place tags in $70 \%$ ethanol solution for 20 min.

2. Remove tags using plastic tweezers and place in small glass dish containing sterile water.

3. Remove tags and place on a sterile pill cup.

\section{Prepare anesthetic solution (timing 5 minutes)}

1. In a small plastic cup weigh $40 \mathrm{~g}$ of Tricaine.

2. Dissolve powder and tap water into a $500 \mathrm{~mL}$ beaker on a stirrer plate with mixer bar and then transfer to a plastic bottle to achieve an $80 \mathrm{~g} / \mathrm{L}$ stock solution.

3. Repeat the same procedure with sodium bicarbonate and add to a separate $500 \mathrm{~mL}$ bottle.

4. Using a $10 \mathrm{~L}$ plastic tub container, fill with $5 \mathrm{~L}$ water (same water source as fish to be tagged).

5. Add $6.25 \mathrm{~mL}$ of Tricaine anesthetic solution and $6.25 \mathrm{~mL}$ of sodium bicarbonate using a measuring pouring gage attached to the top of the $500 \mathrm{~mL}$ bottles to obtain a $100 \mathrm{mg} / \mathrm{L}$ dose to the tub.

6. Stir to mix solution in water. NOTE: Have a lid available to cover the tub to ensure lamprey do not escape while in the anesthetic solution.

\section{Lamprey tagging (timing $\sim 6$ minutes)}

1. Place juvenile lamprey $(>140 \mathrm{~mm}$ ) into anesthetic bath using a small dip net.

2. Wait 4-5 min for lamprey to become fully demobilized (no longer swimming in solution, while maintaining a slow by steady gill movement).

3. Use a dip net to remove lamprey, take length and weight measurements and record the unique identification code of the acoustic tag.

4. Prepare a $1.3 \mathrm{~cm}$ thick closed-cell foam pad saturated with water first and then $150 \mu \mathrm{L} / \mathrm{L}$ protective coating (see Table of Materials). The protective coating helps to counteract the disruption of mucus membranes during surgical procedure.

5. Place the lamprey ventral side up on the prepared foam. Position a small section of tubing with regulated water supply (from an elevated water tank) to flow through the mouth region during the surgical process. This allows for respiration while fish is undergoing tag implantation.

6. Locate the site where incision is to be made, $\sim 20 \mathrm{~mm}$ posterior to the gill pores on the left or right lateral side. Use a ruler with makings or use markers placed on the foam pad for reference.

7. Using a sterile $3.0-\mathrm{mm}$ microsurgical scalpel with a $15^{\circ}$ blade (see Table of Materials) carefully make a $2.5-3 \mathrm{~mm}$ opening in the lateral direction ensuring that the scalpel is cutting just through the inner skin wall. See Figure 1.

8. Place the disinfected tag anteriorly into the body cavity by hand. Apply slight pressure to the tagging site to ensure that the tag has moved into the body cavity.

9. Place tagged lamprey into a recovery bucket containing fresh river water supplied with a fish tank oxygen pump, tubing, and air stone.

10. Ensure that lamprey have recovered from the anesthetic and transfer to holding tank for future study.

\section{Eel tagging (timing $\sim 6$ minutes)}

1. Replicate tag preparation and prepare anesthetic with a concentration dose of $240 \mathrm{mg} / \mathrm{L}$ for both Tricaine and sodium bicarbonate.

2. Add $15 \mathrm{~mL}$ of each to the $5 \mathrm{~L}$ water bath.

3. Place juvenile eels $(>130 \mathrm{~mm}$ ) into anesthetic bath using a small dip net. Wait 4-5 min for eel to become fully demobilized (no longer swimming in solution while maintaining a slow but steady gill movement).

4. Use a dip net to remove eel and place ventral side up on a closed-cell foam coated with Fish Protector.

5. Locate the site where incision is to be made, $\sim 25 \mathrm{~mm}$ to the base of the pectoral fin on the left or right lateral side

6. Using a sterile $3.0-\mathrm{mm}$ microsurgical scalpel with a $15^{\circ}$ blade carefully make a $2.5-3 \mathrm{~mm}$ opening in the lateral direction ensuring that the scalpel is cutting just through the inner skin wall. See Figure 2.

7. Place the disinfected tag anteriorly into the body cavity by hand. Apply slight pressure to tagging site to ensure tag has moved into the body cavity.

8. Place tagged eels into a recovery bucket containing fresh river water supplied with a fish tank oxygen pump, tubing, and air stone.

9. Ensure that eel has recovered from the anesthetic and transfer to holding tank for future study. 


\section{Representative Results}

Juvenile Lamprey Laboratory Studies

A study was conducted at PNNL in 2015 to determine the feasibility of implanting a dummy lamprey/eel tag in actively migrating juvenile Pacific Lamprey. A total of 195 Pacific Lamprey (macrophthalmia life stage) were transported from a field collection site to PNNL. Two separate tasks were conducted. The first was to determine how fish respond to tag implantation. The variables determined included tag loss, delayed mortality, and healing rates for tagged fish as compared to an untagged (control) group. For the second task swim trials were conducted with tagged and untagged fish from $10 \mathrm{~mm}$ size categories $(120-160 \mathrm{~mm}$ ) to determine any adverse effects associated with swimming ability. Fish weights ranged from 1.8 to $7.0 \mathrm{~g}$ and tag burdens ranged from 4.8 to $1.25 \%$. An x-ray illustrating the tag location inside the body cavity is shown in Figure $3^{1}$. A total of two fish dropped their tags during the first 2 days of holding and no additional dropped tags were found during the remainder of the 28day holding period. The cumulate mortality during this period was $14.3 \%$ ( 7 fish) for the tagged lamprey and $9.6 \%$ ( 5 fish) for the control group. Individual tagged and control fish were placed in a swimming chamber and swam at a constant water velocity of $11 \mathrm{~cm} / \mathrm{s}$. The flow rate was selected based on previous laboratory testing which indicated a constant swimming motion at the lower end of the sustained swimming ability ${ }^{9}$. The mean swim time of the control group was $3.15 \mathrm{~min}(\mathrm{SE}=42.5 \mathrm{~s}$ ) and the mean swim time of the implanted group was 2.3 min (SE = $30.2 \mathrm{~s}$ ), which was not a significant difference $(t=0.958 ; p=0.172)$. The results from the swimming performance tests showed no significant correlation between fish length and swimming duration (i.e., time to impingement) for either the tagged or control groups (Figure 4). Impingement is described as the fish no longer able to swim at the constant water velocity and rested at the downstream screen.

\section{American Eel Laboratory Studies}

To determine any possible I tag effects on swimming performance, we conducted critical swimming speed tests using $U_{\text {crit }}$ (an index of prolonged swimming performance) for six size groups $(n=120 ; 113-175 \mathrm{~mm}$ ) of untagged and tagged eels using dummy tags which measured $11.4 \mathrm{~mm}$ $x 1.8 \mathrm{~mm}$ (length $\mathrm{x}$ diameter) ${ }^{1}$. There was no significant difference in $U_{\text {crits }}$ between tagged and untagged eels as measured in $\mathrm{cm} / \mathrm{s}(\mathrm{Figure} 5)$ or median values measured in body length/s for all tagged and untagged groups combined (Figure 6). We also conducted a prolonged holding of tagged eels ( 38 days) and found no mortality from the tagged groups and a low tag loss of $3.8 \%$ ( 1 out of 26 fish) ${ }^{1}$. Based on our laboratory results, we conclude that micro acoustic tags can be effectively implanted in juvenile American eels with no significant effects on swimming ability, long term survival and had minimal tag loss during the tag life (30 days). 


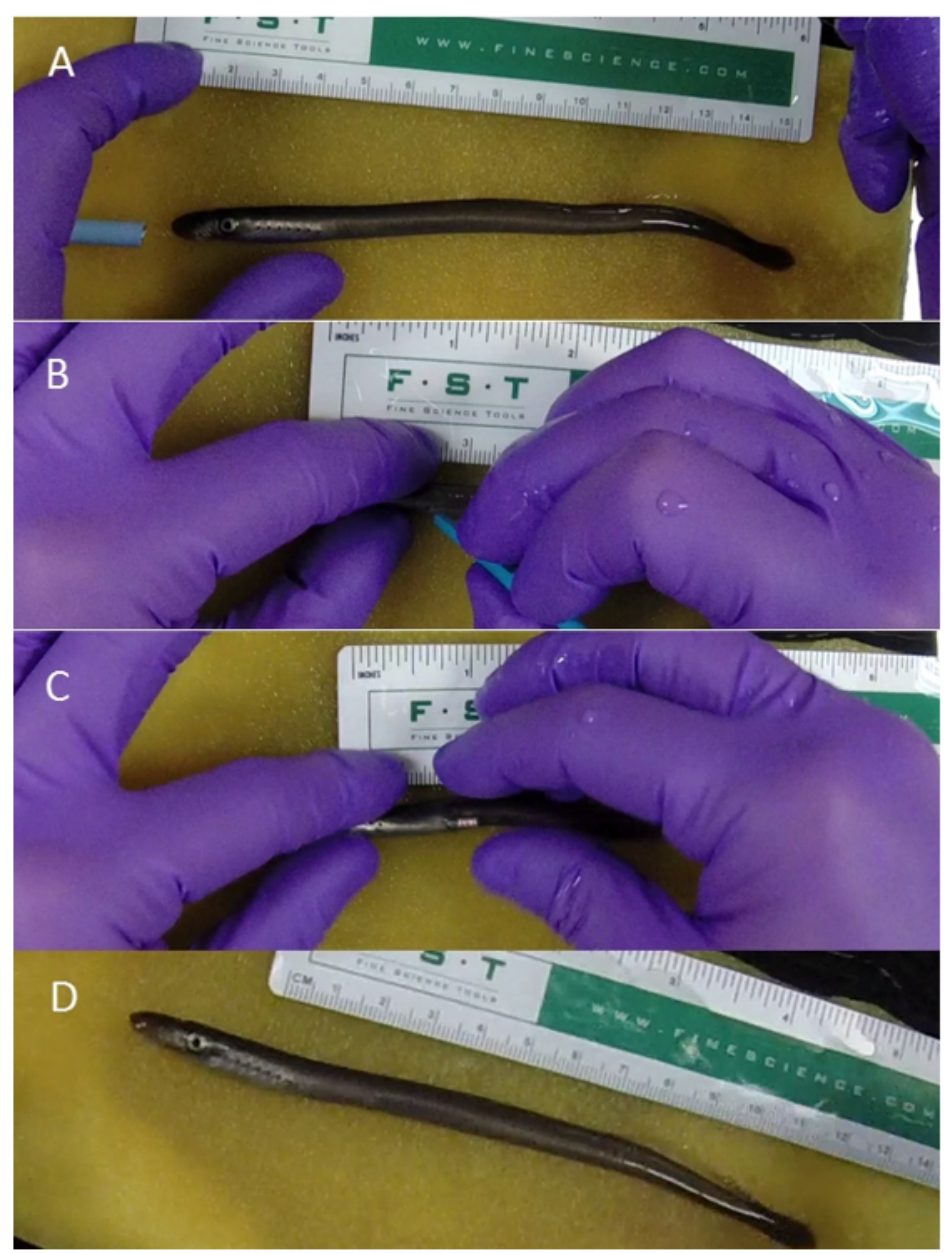

Figure 1. Photographs illustrating tagging sequence for tag insertion in juvenile Pacific Lamprey. (A) Lamprey positioned on foam pad. (B) Incision made with microsurgical scalpel. (C) Tag being implanted. (D) Lamprey post-tagging. All pictures were taken of the same lamprey $(148 \mathrm{~mm})$. 


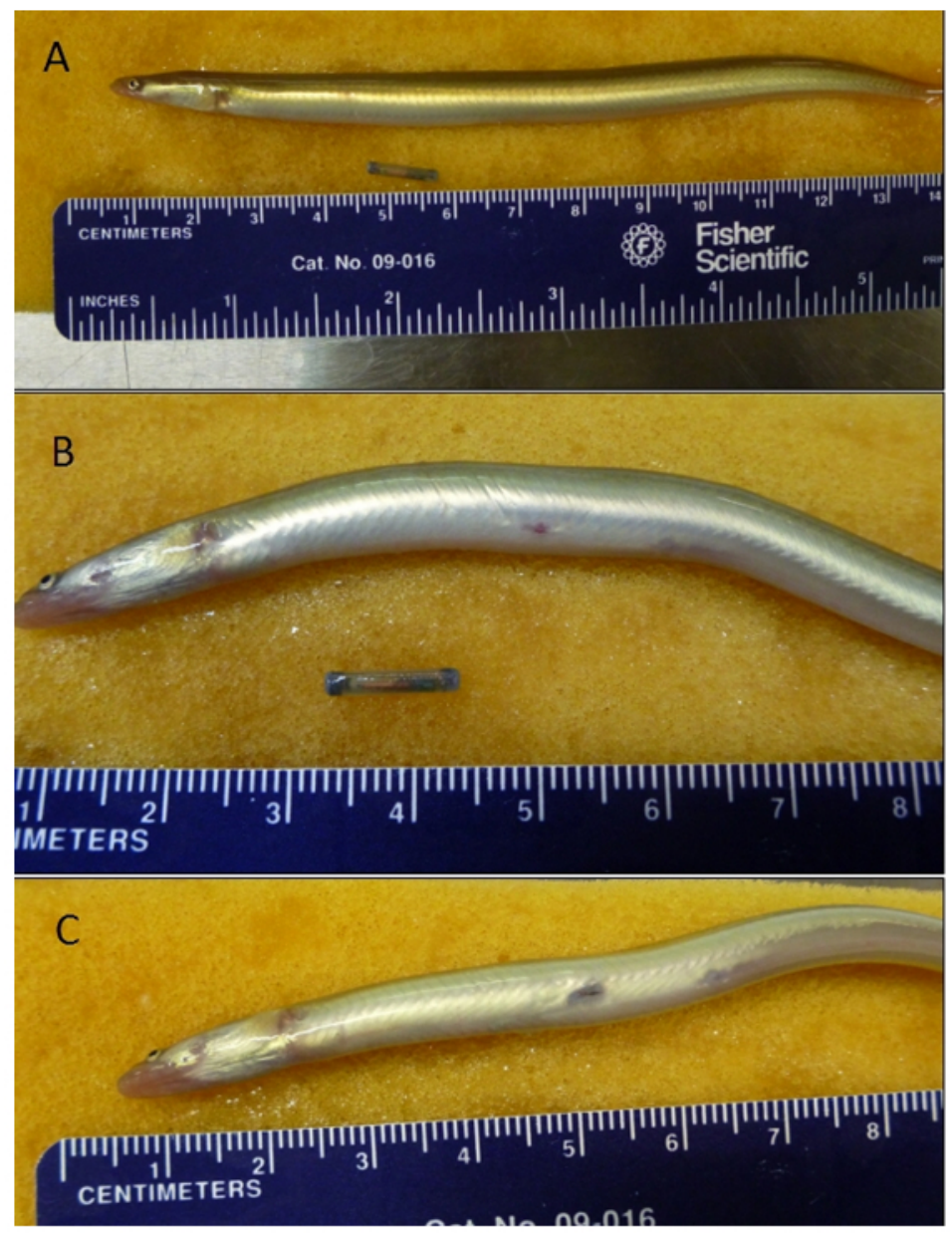

Figure 2. Photographs illustrating tagging procedure for juvenile American Eels. (A) Before incision. (B) After incision. (C) After anterior insertion of the tag. All pictures were taken of the same eel $(138 \mathrm{~mm})$.
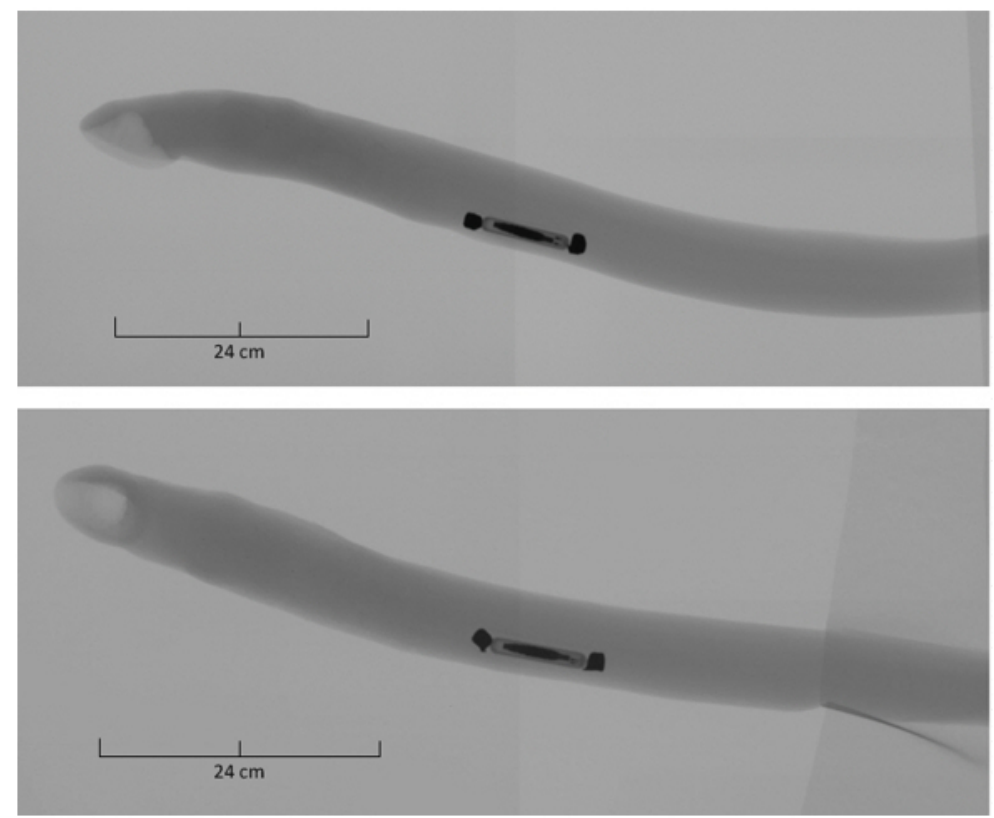

Figure 3. X-ray images of dummy lamprey/eel tag inside the body cavity of a juvenile Pacific Lamprey. 


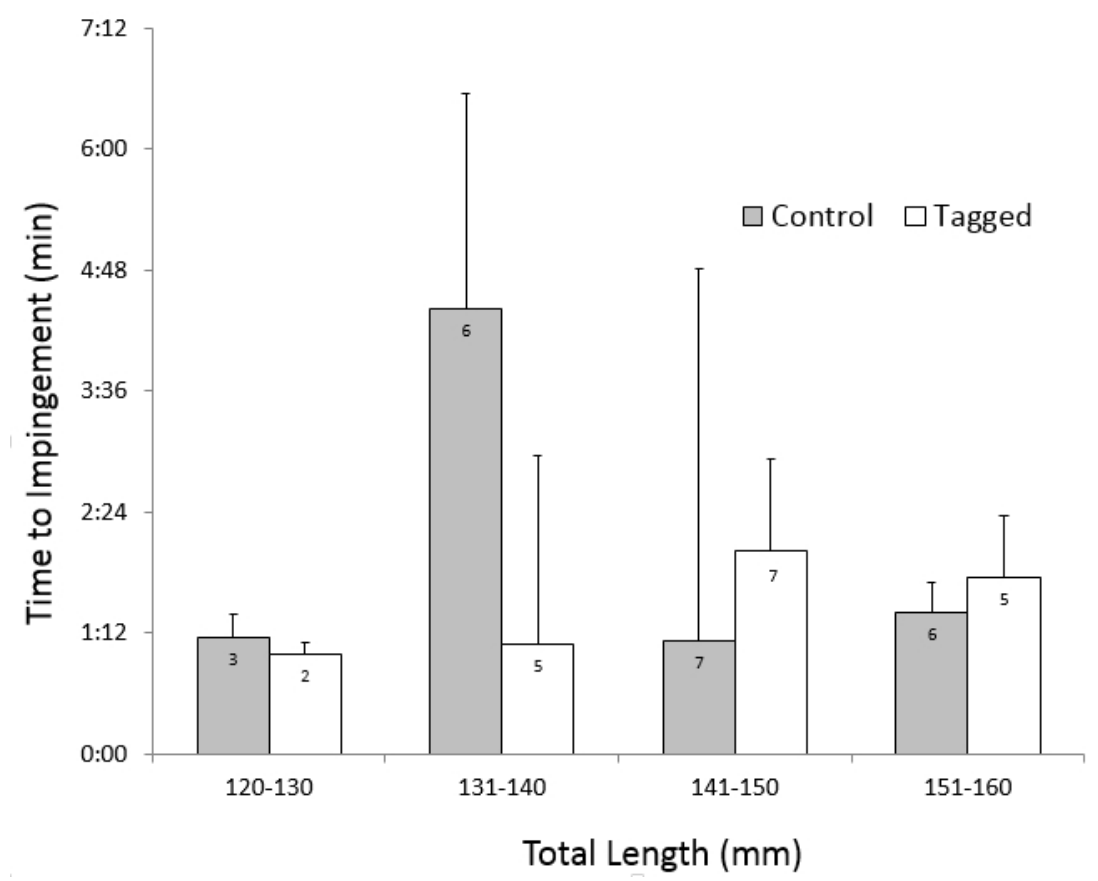

Figure 4. Impingement rates from swimming performance tests for control (untagged) and tagged lamprey, separated into $10 \mathrm{~mm}$ size categories with positive standard error bars. Sample sizes are listed in the individual bars.

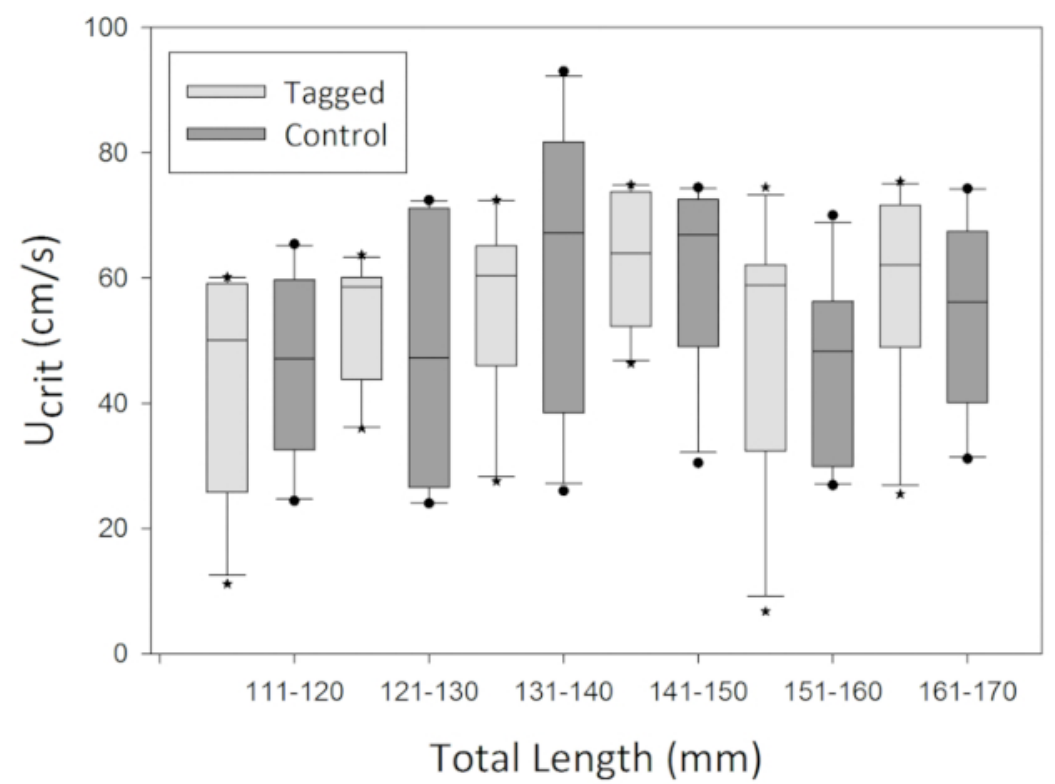

Figure 5. Box plots of critical swimming speed for size groups of eels tested in $\mathrm{cm} / \mathrm{s}$ for tagged and untagged eels (10 per treatment). The lines within each box represent the median; the top and bottom lines represent the 75th and 25th percentiles, respectively; the whiskers are the top 90th and bottom 10th percentiles; and the outliers are depicted by enclosed circles. 


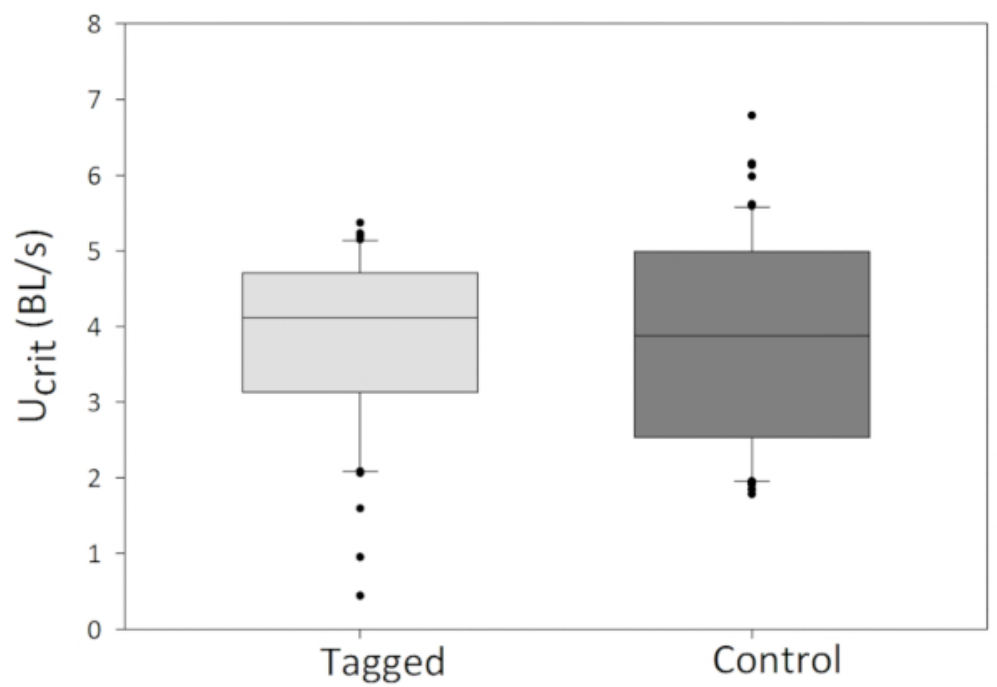

Figure 6. Box plots of critical swimming speed in body length/s for tagged and untagged eels (10 per treatment). The lines within each box represent the median; the top and bottom lines represent the 75th and 25th percentiles, respectively; the whiskers are the top 90th and bottom 10th percentiles; and the outliers are depicted by enclosed circles.

\section{Discussion}

The results of the laboratory studies demonstrate that the tagging procedure and tagging effects do not have adverse effects on fish survivability or swimming ability. Extended holding and monitoring showed that minimal tag loss occurred and was not apparent during the tag life (30 days). The tag implantation procedure was effective at placing tags in the body cavity without causing significant hemorrhaging or fungal infections at the tagging site. The duration of the entire tagging process ( $<6 \mathrm{~min})$ is beneficial in that it reduces stress associated with the fish being anesthetized. These findings characterize a new tool for juvenile lamprey and eel passage research and can be utilized in future studies. This technology will allow researchers to track lamprey and eel movements within river systems and as they approach hydroelectric dams or other structures that impede fish passage. In turn, the results can better inform management decisions at these facilities to help conserve these species throughout their juvenile life stages. The most critical steps of the tag implantation protocol include using the proper dose of anesthetic, depth and length of the incision, placement of the tags, and having the proper recovery holding tanks available. This technique has minimal limitations. Most notably, surgeon training is required to effectively make the $<3 \mathrm{~mm}$ incision and place the tags at the desired location. Additionally, the tagging process would exclude smaller sized eels and lamprey $(<140 \mathrm{~mm})$ due to tag burden limitations. We do not recommend any modifications to the described protocols.

Alternate methods for tagging eels and lamprey include the use of PIT tags. However, PIT-tags do not actively transmit signals, therefore PITtagged fish can only be enumerated as they are entrained and diverted into bypass facilities, or pass close to a fixed detector ${ }^{10,11}$. Future applications of the lamprey/eel tag include the ability to tag and track populations of migrating lamprey and eels in any environment they inhabit. Additional benefits of using the lamprey/eel tag would include the ability to estimate survival, fallback rates at spillways or via turbines, travel time within reservoirs, passage delays and related behavior as fish approach dams.

\section{Disclosures}

We have nothing to disclose.

\section{Acknowledgments}

This study was funded by the U.S. Army Corps of Engineers (USACE) and the U.S. Department of Energy (DOE) Water Power Technologies Office. We appreciate the technical assistance from the following PNNL staff: Colin Brislawn, Eric Francavilla, Jill Janak, Huidong Li, and Tim Linley. We thank Kathy Kratchman from Delaware Valley Fish Company for supplying eels to PNNL and Ralph Lampman and Tyler Beals from the Yakama Nation Fisheries for supplying the lamprey. We also thank Brad Eppard, Scott Fielding, and Ricardo Walker from the USACE and Dana McCoskey and Tim Welch from the DOE. The laboratory studies were conducted at PNNL, which is operated by Battelle for the U.S. Department of Energy underContractDE-AC06-76RL01830.

\section{References}

1. Mueller, R.P. et al. Retention and Effects of Miniature Transmitters in Juvenile American Eels. Fisheries Research. 195, 52-58 (2017).

2. Brown, R.S. et al. An evaluation of the maximum tag burden for implantation of acoustic transmitters in juvenile Chinook salmon. North American Journal of Fisheries Management. 30, 499-505 (2010).

3. Jepsen, N., Schreck, C., Clement, S., Thorstad, E. A brief discussion of the $2 \%$ tag/bodymass rule. Aquatic telemetry: advances and applications. M. T. Spedicato, G. Marmulla, G. Lembo (eds.). FAO - COISPA, Rome. 255-259 (2003). 
4. Liedtke, T. L.,et al. A standard operating procedure for the surgical implantation of transmitters in juvenile salmonids. U.S. Geological Survey Open File Report 2012-1267. (2012).

5. Deng, Z.D., et al. 2011. A cabled acoustic telemetry system for detecting and tracking juvenile salmon: Part 2. Three-dimensional tracking and passage outcomes. Sensors. 11 (6), 5661-5676 (2011).

6. Titzler, P.S., McMichael, G.A., Carter, J.A. 2010. Autonomous acoustic receiver deployment and mooring techniques for use in large rivers and estuaries. North American Journal of Fisheries Management. 30 (4), 853-859 (2010).

7. Renaud, C.B. Conservation status of northern hemisphere lampreys (Petromyzontidae). Journal of Applied Ichthyology. 13 (3), $143-148$ (1997).

8. Dauble D.D, Moursund R.A, Bleich, M.D. Swimming behavior of juvenile Pacific lamprey, Lampetra tridentata. Environmental Biology of Fishes. 75, $167171(2006)$.

9. Moursund, R.A., Dauble D.D., Langeslay, M.J. Turbine intake diversion screens; investigating effects on Pacific lamprey. Hydro Review. 22 (1), 40-46(2003)

10. Marsh, D. M., Matthews G. M., Achord, S., Ruehle, T. E., Sandford B. P. Diversion of salmonid smolts tagged with passive integrated transponders from an untagged population passing through a juvenile collection system. North American Journal of Fisheries Management. 19, 1142-1146 (1999).

11. Prentice, E. F., Flagg T. A., McCutcheon C.S. Feasibility of using passive integrated transponder (PIT) tags in salmonids. in N. C. Parker, A E. Giorgi, R. C. Heidinger, D. B. Jester, Jr., E. D. Prince, and G. A. Winans, editors. Fish marking techniques. American Fisheries Society, Symposium . 7, 317-322 (1990).

12. Colotelo, A.H.et al. The effect of rapid and sustained decompression on barotrauma in juvenile brook lamprey and Pacific lamprey: Implications for passage at hydroelectric facilities. Fisheries Research. 129130 , 17-20 (2012).

13. Moser, M.L., Jackson, A.D., Lucas, M.C., Mueller, R.P. Behavior and potential threats to survival of migrating lamprey ammocoetes and macrophthalmia. Reviews in Fish Biology and Fisheries. 25 (2), 103-116 (2015).

14. Dixon, D.A. Biology, management, and protection of catadromous eels. American Fisheries. Society Symposium. 33 (2003).

15. ASMFC (Atlantic States Marine Fisheries Commission), Update of the American eel stock assessment report. ASMFC, 51 pp (2006).

16. DFO (Fisheries and Oceans Canada), Recovery potential assessment of American Eel (Anguilla rostrata) in eastern Canada. DFO Canadian Science Advisory Secretariat Scientific Advisory Report. (2013).

17. MacGregor, R.Jet al. Recovery Strategy for the American Eel (Anguilla rostrata.) in Ontario. Ontario Recovery Strategy Series. Prepared for Ontario Ministry of Natural Resources, Peterborough, Ontario. $x+119$ pp (2013).

18. Deng Z, Weiland, M.A., Carlson, T.J., Eppard, M.B. Design and Instrumentation of a Measurement and Calibration System for an Acoustic Telemetry System. Sensors. 10 (4), 3090-3099 (2010).

19. Cook, K. V. et al. A comparison of implantation methods for large PIT tags or injectable acoustic transmitters in juvenile Chinook salmon. Fisheries Research. 154, 213-223 (2014).

20. Mesa, M.G., et al. Survival and Growth of Juvenile Pacific Lampreys Tagged with Passive Integrated Transponders (PIT) in Freshwater and Seawater. Transactions of the American Fisheries Society. 141 (5), 1260-1268 (2012).

21. Brown, R.S., Cooke, S.J., Anderson, W.G., McKinley, R.S. Evidence to challenge the $2 \%$ rule for biotelemetry. North American Journal of Fisheries Management. 19, 867-871(1999).

22. Zale, A.V., Brooke, C., Fraser, W. C. Effects of surgically implanted transmitter weights on growth and swimming stamina of small adult westslope cutthroat trout. Transactions of the American Fisheries Society. 134 (3), 653-660 (2005).

23. Geist, D.R. et al. Juvenile Chinook salmon survival when exposed to simulated dam passage after being implanted with a new microacoustic transmitter. North American Journal of Fisheries Management.10.1002/nafm.10198 (2018).

24. Økland, F., Thorstad, E.B. Recommendations on size and position of surgically and gastrically implanted electronic tags in European silver eel. Animal Biotelemetry. 1, 6 (2013).

25. Jepsen, N., Mikkelsen, J. S., Koed, A. Effects of tag and suture type on survival and growth of brown trout with surgically implanted telemetry tags in the wild. Journal of Fish Biology. 72, 594-602 (2008).

26. Brown, R.S.et al. Survival of seaward-migrating PIT and acoustic-tagged juvenile Chinook salmon in the Snake and Columbia Rivers: an evaluation of length-specific tagging effects. Animal Biotelemetry. 1, 8 (2013).

27. Walker, R. et al. Effects of a novel acoustic transmitter on swimming performance and predator avoidance of juvenile Chinook salmon: Determination of a size threshold. Fisheries Research. 176, 48-54 (2016). 